\title{
Tooling up to facilitate findability, virtual collaboration, and storytelling with data*
}

\author{
Susan Lessick, MA, MLS, AHIP, FMLA
}

See end of introduction for author's affiliation.

\section{INTRODUCTION}

Technology matters more than ever in these challenging times. Given the competition between library services and the commercial sector, tight funding climate, and increasing calls for transparency and accountability, we need to take advantage of all the tools at hand. Technology tools provide critical opportunities for health sciences libraries to connect users to sought-after resources in an ever-deepening pool of available research, scholarship, and data; problem solve to achieve efficiencies and cost savings; reach out to users in ways more potent than ever; and strengthen and expand the role of the library within the institution and beyond.

Every year, this column recognizes a handful of health sciences librarians and libraries for projects that use technology in innovative ways. Virtual projects refer to successful implementations of technological advancements and their real-world use in library environments - particularly those that extend services beyond the bounds of the physical library experience. An advisory committee of technology experts annually reviews submissions and selects those few that best demonstrate new technologies or applications of technologies that creatively solve problems, strengthen services, engage users, and are replicable at other health sciences libraries or contain elements that will be transferable to other settings. Thus, these inspiring projects warrant closer attention by the health sciences library community.

\footnotetext{
* Material for this column is selected with the assistance of the Journal of the Medical Library Association Virtual Projects Column Advisory Committee: Patricia F. Anderson, Taubman Health Sciences Library, University of Michigan; Janis F. Brown, AHIP, Norris Medical Library, University of Southern California; Michelle Kraft, AHIP, Cleveland Clinic Alumni Library, Cleveland Clinic; Dale Prince, AHIP, National Network of Libraries of Medicine, Southeastern Region (NN/LM SE/A), University of Maryland; and Elizabeth C. Whipple, AHIP, Ruth Lilly Medical Library, Indiana University.
}

DOI: http://dx.doi.org/10.3163/1536-5050.104.4.021
We are pleased to present five technology projects that have successfully addressed issues that are common to health sciences libraries everywhere. This year's "technology laureates" stand apart for their innovation and relevance. Two librarians at Yale University created an ingenious search tool that enhances the efficiency of the comprehensive search process for the expert searchers at their library and across the country. Librarians from the University of Pittsburgh creatively developed the first-ever federated search engine for multiple preprint servers to help researchers quickly discover biomedical research in a preprint format. For the first time in this column, we are featuring a virtual project sponsored by a Medical Library Association chapter. The Midcontinental Chapter of the Medical Library Association took a risk and succeeded in offering an all-virtual annual meeting. What made the difference? Check out the authors' thoughtful lessons learned from their all-virtual conference experience. Because metrics matter, especially when it comes to fostering evidence-based librarianship (EBL) and public confidence in libraries, we are excited to highlight the Penn State dashboard project, which impressively communicates the library's value and impact on the community it serves. Finally, we want to spotlight the stunning infographics work of a librarian serving in a new, emerging role for medical librarians, that of a research and evaluation analyst, at the University of Massachusetts Center for Clinical and Translational Science. It is our hope and expectation that these projects will engender learning, spur action, and build capacity for continued work in the area of library technology to continuously reshape services to meet the evolving needs of our users.

Please consider sharing your own virtual project in future columns to inspire your colleagues to embrace and leverage technology tools to transform services, workflows, and outreach. Submissions, suggestions, and questions should be 
directed to Susan Lessick, AHIP, FMLA, at slessick@uci.edu.

Susan Lessick, MA, MLS, AHIP, FMLA, slessick@ uci.edu, Librarian Emerita, Grunigen Medical Library, University of California, Irvine, 7468 East Calle

Durango, Anaheim, CA 92808

\section{THE YALE MESH ANALYZER: USING TECHNOLOGY TO MAKE SEARCHING MORE EFFICIENT}

Submitted by Lei Wang, MSI; Holly K. Grossetta Nardini, MLS; Cushing/Whitney Medical Library, Yale University

Over the last few years, health sciences librarians have seen a significant rise in mediated search requests and served on research teams doing systematic reviews and meta-analyses with increasing frequency [1]. While it is professionally gratifying to have patrons recognize our unique value and expertise, the amount of work this creates can be overwhelming. Without additional staff, libraries need to modify their workflows to achieve greater efficiency. This article describes one example of how custom technological tools can be created to save time in a comprehensive search process.

Scoping searches and search validation are two time-consuming steps in a comprehensive search project. The first is used to discover all relevant search terms, and the second verifies that no known relevant articles are missing. At Yale, librarians typically ask researchers they work with for five to ten key articles that should appear in the final search

\begin{tabular}{|c|c|c|c|}
\hline 25599822 & 25705687 & 15956199 & 21148108 \\
\hline Govindaraj V (2015) & Zhu L (2015) & Ledent C (2005) & $\operatorname{Lim} \mathbf{J}(2011)$ \\
\hline $\begin{array}{l}\text { Aging } \\
\text { Animals }\end{array}$ & \multicolumn{2}{|c|}{ "Aging" is missing in 2 articles. } & $\begin{array}{l}\text { Aging } \\
\text { Animals } \\
\text { Antioxidants } \\
\text { Apoptosis }\end{array}$ \\
\hline \multicolumn{4}{|l|}{$\begin{array}{l}\text { BRCA1 Protein } \\
\text { Blotting, Western }\end{array}$} \\
\hline & $\begin{array}{l}\text { Cell Adhesion Molecules } \\
\text { Cyclohexenes }\end{array}$ & & \\
\hline \multirow{2}{*}{$\begin{array}{l}\text { DNA Breaks, Double-Stranded } \\
\text { DNA Repair Enzymes } \\
\text { Down-Regulation }\end{array}$} & Dinoprostone & & DNA Damage \\
\hline & Potential new terms here. & $\begin{array}{l}\text { Embryonic Development } \\
\text { Estrus }\end{array}$ & Estrous Cycle \\
\hline Female & $\begin{array}{l}\text { Female } \\
\text { Follicle Stimulating Hormone, Human }\end{array}$ & $\begin{array}{l}\text { Eemale } \\
\text { Follicle Stimulating Hormone }\end{array}$ & Female \\
\hline $\begin{array}{l}\text { Gene Expression Regulation, Developmental } \\
\text { Gene Expression Regulation, Enzymologic } \mathrm{Th}\end{array}$ & $\begin{array}{l}\text { Gene Expression Regulation } \\
\text { he concept of gene express }\end{array}$ & $\begin{array}{l}\text { Genetic Vectors } \\
\text { sion is indexed differently. }\end{array}$ & $\begin{array}{l}\text { Gene Expression } \\
\text { Glutaredoxins } \\
\text { Glutathione Transferase }\end{array}$ \\
\hline \multirow[t]{3}{*}{ Histones } & Humans & & \\
\hline & Luteinizing Hormone & & Lipid Peroxidation \\
\hline & & $\begin{array}{l}\text { Mice } \\
\text { Mice, Knockout }\end{array}$ & $\begin{array}{l}\text { Mice } \\
\text { Mice, Inbred C57BL }\end{array}$ \\
\hline $\begin{array}{l}\text { Ovarian Follicle } \\
\text { The concept of ov }\end{array}$ & rary is indexed differently. & $\begin{array}{l}\text { Oocytes } \\
\text { Ovary }\end{array}$ & $\begin{array}{l}\text { Organ Size } \\
\text { Ovary } \\
\text { Oxidative Stress }\end{array}$ \\
\hline $\begin{array}{l}\text { Phosphoproteins } \\
\text { Phosphorylation } \\
\text { Protein Processing, Post-Translational }\end{array}$ & $\begin{array}{l}\text { Panax } \\
\text { Plant Extracts } \\
\text { Primary Ovarian Insufficiency }\end{array}$ & & $\begin{array}{l}\text { Peroxiredoxin III } \\
\text { Peroxiredoxins }\end{array}$ \\
\hline \multirow[t]{4}{*}{$\begin{array}{l}\text { RNA, Messenger } \\
\text { Rad51 Recombinase } \\
\text { Rats, Wistar } \\
\text { Real-Time Polymerase Chain Reaction } \\
\text { Reverse Transcriptase Polymerase Chain } \\
\text { Reaction }\end{array}$} & Rats & $\begin{array}{l}\text { RNA, Messenger } \\
\text { Receptors, G-Protein-Coupled } \\
\text { Reverse Transcriptase Polymerase Chain } \\
\text { Reaction }\end{array}$ & RNA, Messenger \\
\hline & & Superovulation & \\
\hline & & & Thioredoxins \\
\hline & Vinyl Compounds & & \\
\hline Xeroderma Pigmentosum Group D Protein & & & \\
\hline
\end{tabular}

Figure 1

Manual Medical Subject Headings (MeSH) analysis grid 
Type or paste in up to 20 PMIDs ...
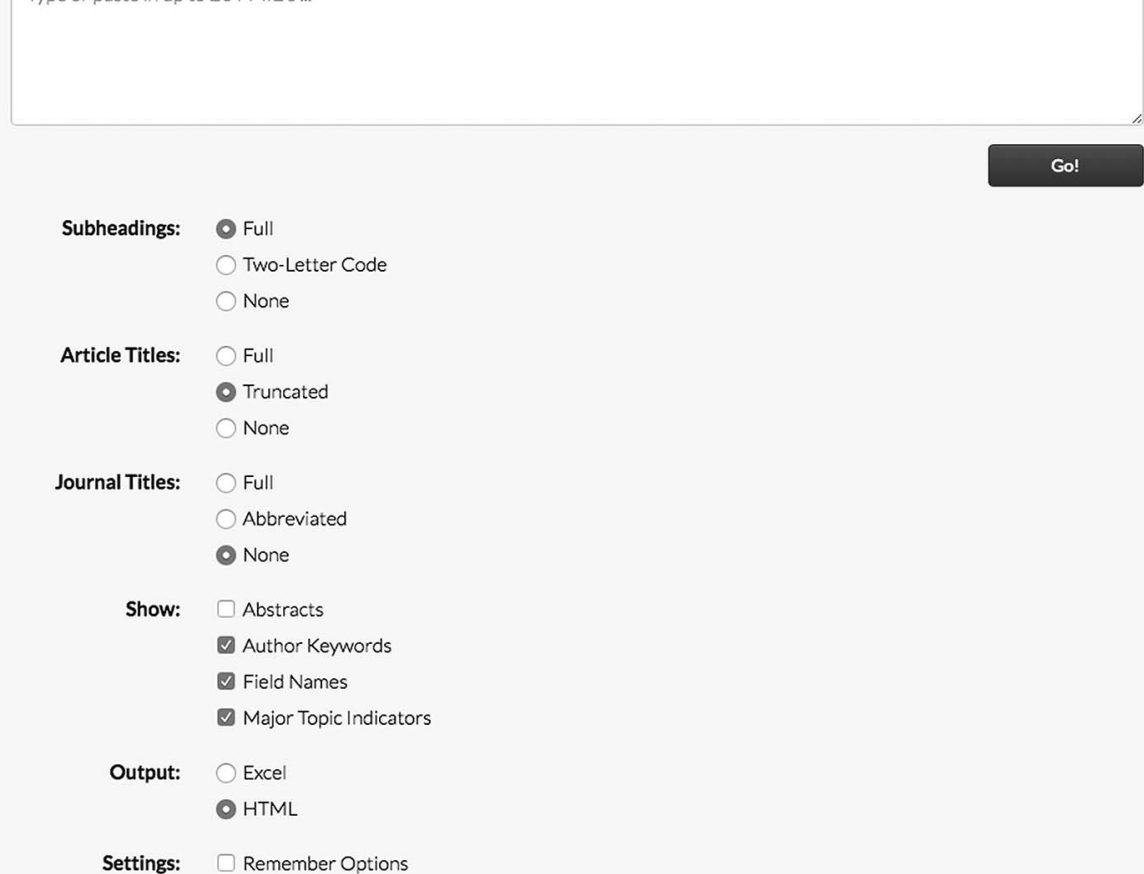

\section{Figure 2}

Yale MeSH Analyzer user interface

results. Those key articles are used to generate search terms and validate search strategies. However, even a carefully crafted search can still miss important terms, as well as known relevant articles.

Librarians have always tried to refine searches by closely examining the Medical Subject Headings (MeSH) assigned to articles in MEDLINE. Based on work by Janis Glover [2], we had been manually creating $\mathrm{MeSH}$ analysis grids to compare article indexing (Figure 1). Each column in a grid represented an article, with identifying information (PMIDs, authors, and years) at the top of a grid. $\mathrm{MeSH}$ terms were sorted and grouped alphabetically. Scanning the grid helped searchers discover potentially useful MeSH terms and identify why some articles were retrieved by a search, but others were not. This might be due to indexing inconsistencies or problems with the search strategy itself, such as missing terms or flawed syntax.

However, creating such grids required at least twenty minutes of work. Metadata for each article must be manually retrieved, copied and pasted into a grid, and the MeSH terms must be manually sorted and grouped. In 2015, we created the Yale MeSH Analyzer $<$ http://mesh.med.yale.edu $>$ to remove the inefficiency and tediousness from the process. With the Yale MeSH Analyzer, we can now simply paste or type a list of PMIDs in the text box and click "Go." The automated grid that is produced can be output either as a Microsoft Excel spreadsheet or as a hypertext markup language (HTML) page. The grid can also include article titles, author-assigned keywords, and abstracts to help identify new terms and phrases and enhance the search (Figure 2).

The Yale MeSH Analyzer uses the National Center for Biotechnology Information's (NCBI's) Entrez Programming Utilities Help (E-utilities API) $<$ http:// eutils.ncbi.nlm.nih.gov $>$ as the back end, which returns data in extensible markup language (XML) format when queried. Behind the scenes, the analyzer scans the user's input for PMIDs, constructs a query using those PMIDs, and sends it to the Eutilities API. Once it receives the response from 
NCBI, the analyzer parses the XML document, extracts the fields it needs, and builds the grid using a standard template plus any options that the user selects on the interface. A browser bookmarklet for the analyzer is also available to use when searching directly on PubMed. The bookmarklet extracts selected records from a PubMed search results page (known as "scraping") and sends them to the analyzer to generate a grid. Additionally, a user can click the "Help" button for detailed instructions, an example grid, and a demonstration video.

To accomplish a routine task that is otherwise timeconsuming, users can with a click of a button, greatly improve their efficiency in the comprehensive search process. For this reason, the analyzer has been well received among librarians and researchers. Google Analytics reported over 9,000 user sessions during the period from October 2015 to May 2016.

Creating and managing a web-based tool require a sustained institutional commitment. Since its inception, the Yale MeSH Analyzer has had multiple versions. Users from around the world have provided valuable feedback, which encouraged us to add new features and improve the tool's performance. Since its launch, we have added options to include journal titles and $\mathrm{MeSH}$ major topic indicators, a new video tutorial on the "Help" page, a rigorous testing protocol when rolling out new versions of the application, and an NCBI E-utilities API status monitor, which alerts users when there is a problem. The Yale MeSH Analyzer is an example of a homegrown tool designed to streamline an otherwise tedious process that has taken wing and improved searching efficiency well beyond its walls.

Lei Wang, MSI, lei.wang@yale.edu, Instructional Design Librarian, Cushing/Whitney Medical Library, Yale University, 333 Cedar Street, New Haven, CT 065208014

\section{REFERENCES}

1. Lefebvre C, Glanville J, Wieland LS, Coles B, Weightman AL. Methodological developments in searching for studies for systematic reviews: past, present and future? Syst Rev. 2013 Sep;25(2):78. DOI: http://dx.doi.org/10.1186/2046-4053-2-78.

2. Glover J, Odato K. Advanced searching in support of systematic reviews [Internet]. New Haven, CT: Cushing/Whitney Medical Library; 2012 [cited 26 Jun 2016]. <http://library.medicine.yale.edu/sites/ default/files/tutorials/files/glover_odato_sys_review. pdf $>$.

\section{DISCOVERY TOOL FOR LIFE SCIENCES RESEARCH ARTICLE PREPRINTS}

\section{Submitted by Carrie L. Iwema, PhD, MLS, AHIP; John LaDue, MLIS; Angela Zack, MSIS; Ansuman Chattopadhyay, PhD; Health Sciences Library System, University of Pittsburgh}

The time it takes for a completed manuscript to be published traditionally can be extremely lengthy. Article publication delay, which occurs in part due to constraints associated with peer review, can prevent the timely dissemination of critical and actionable data associated with new information on rare diseases or developing health concerns, such as the Zika virus. Preprint servers are open access online repositories housing research articles that have not yet been peer reviewed or traditionally published. Submission to these sites enables authors to (1) make their research immediately and freely available, and (2) receive commentary and peer review prior to journal submission. Preprint manuscripts are not copyedited, but they do undergo a basic screening process to check against plagiarism, offensiveness, and nonscientific content. Authors may make revisions at any point, but all versions remain available online.

While the number of articles submitted to and hosted by preprint servers appears to be gradually increasing, there has been no simple way to identify biomedical research published in a preprint format. They are not currently indexed in MEDLINE and are only discoverable by directly searching the specific preprint server website. This suggests that many timely and relevant research reports potentially fall through the cracks. To address this issue, in February 2016, the Health Sciences Library System (HSLS) at the University of Pittsburgh developed a tool to help researchers quickly search preprint databases and discover cutting edge, yet-to-be published or reviewed biomedical research articles, search.bioPreprint $<$ http://www.hsls.pitt.edu/ resources/preprint $>$.

Search.bioPreprint uses IBM Watson Explorer (formerly, Vivisimo Velocity) to provide a full-text, meta search engine capability that compiles search term results from a preselected list of multiple sources into a single list, ordered by the relevance of matching query terms (Figure 3). HSLS has used this software repeatedly to develop, implement, and maintain several federated search engines focused on a variety of topics, including search.HSLS.OBRC 


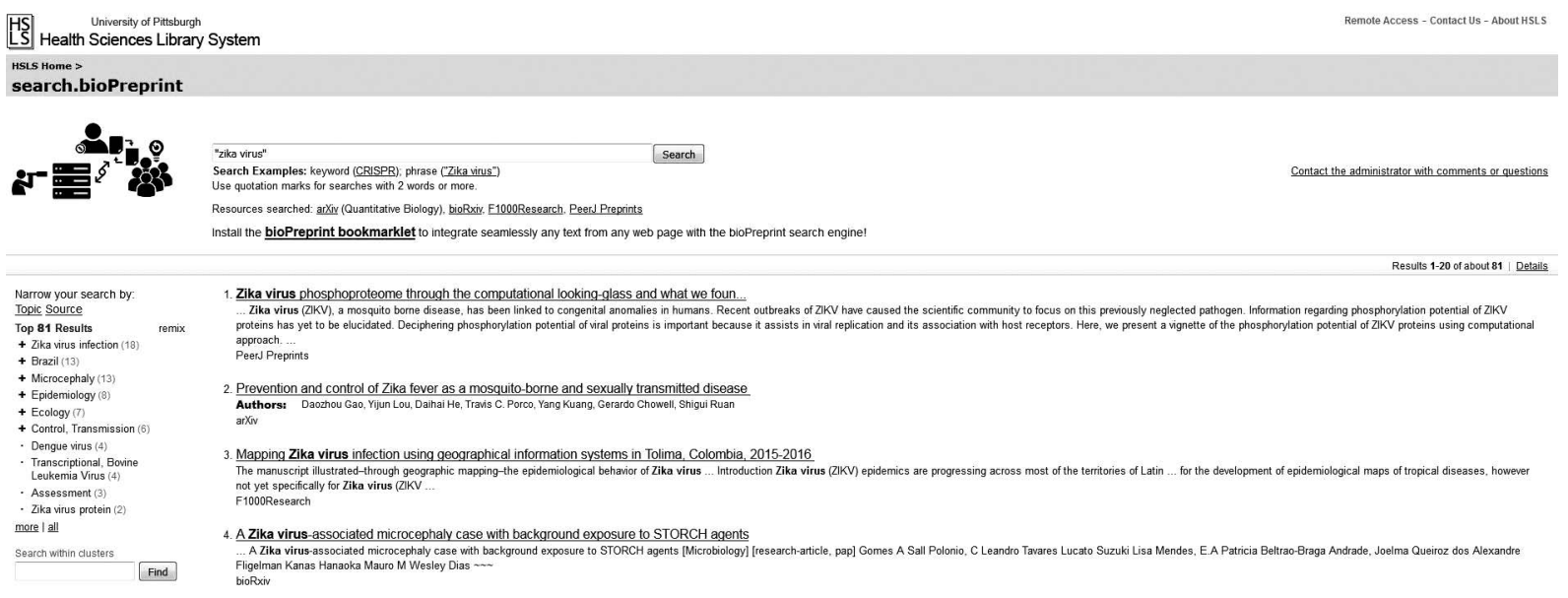

Figure 3

search.bioPreprint results page

$<$ https://www.hsls.pitt.edu/obrc/ $>$, Clinical Focus $<$ http://www.hsls.pitt.edu/clinical $>$, and Clinical eCompanion $<$ http://ecompanion.pitt.edu $>$. Results can then be further filtered by source (preprint servers) or by topic (e.g., microcephaly for a Zika virus search). The topic search is accomplished via clustering, meaning the search results are organized on the fly by similarity in subject matter. Additionally, the "remix" link reveals new secondary topics, which is done by reclustering the same search results. search.bioPreprint's federated search includes four preprint servers catering to biological and biomedical research manuscripts: arXiv $<$ http:// arxiv.org $>$, bioRxiv < http://biorxiv.org $>$, F1000Research $<$ http://f1000research.com $>$, and PeerJ Preprints $<$ https://peerj.com/preprints/>.

The quality of the search results is confined by the search parameters of the individual preprint servers. If the preprint servers alter their search algorithms, a concomitant adjustment of underlying code used by search.bioPreprint is required. Unfortunately, these alterations can be done without any public notification and are only discoverable upon a thorough analysis of search.bioPreprint results. To ensure quality, HSLS has a quality-check team consisting of two experienced and skilled librarians to ensure the accuracy of search.bioPreprint results. In addition, the underlying technology upon which search.bioPreprint is built is flexible enough to integrate additional resources in the future. As new preprint servers are introduced, search.bioPreprint will incorporate them and continue to provide a one-stop solution for finding preprint articles.

Carrie L. Iwema, PhD, MLS, AHIP, iwema@pitt.edu, Information Specialist in Molecular Biology, Health Sciences Library System, University of Pittsburgh, 200 Scaife Hall, 3550 Terrace Street, Pittsburgh, PA 15261

\section{A CHAPTER OF THE MEDICAL LIBRARY ASSOCIATION CONDUCTS AN ALL-VIRTUAL ANNUAL MEETING}

\section{Submitted by Heather L. Brown, MA, AHIP, Chapter Council Representative; Rebecca S. Graves, MLS, AHIP, Annual Meeting Advisor; Midcontinental Chapter of the Medical Library Association}

Faced with declining travel budgets and volunteers to plan and attend annual meetings, librarians and organizations are looking for creative ways to maximize travel dollars and simplify meeting planning. In 2015, the Midcontinental Chapter of the Medical Library Association (MCMLA) < http:// mcmla.org $>$ conducted its annual meeting entirely online after extensive discussions and planning that started in $2010<$ http://mcmla.org/2015meeting >.

A planning committee of twelve MCMLA members, with additional assistance from the MCMLA Education and Research Committees, focused its efforts on the usual processes of promotion, registration, and vendors but added the new process of selecting an online platform. The committee chose a familiar conferencing software, 
AdobeConnect, which was licensed through the vendor MeetingOne < https://www.meetingone.com/ adobe-connect $/>$. This software was chosen based on a cost comparison with other products and MCMLA members' familiarity with the interface. Members have experienced AdobeConnect webinars conducted by the National Network Libraries of Medicine, Midcontinental Region. The features of the software included display of PowerPoint slides and screen sharing, chat support, and interactive polls. Aside from a base fee, the cost was based on the number of logons distributed to registrants. While the software met the basic presentation needs, the polling feature only permitted the selection of preset answers and one vote per site.

The meeting schedule mirrored that of traditional in-person annual meetings: a keynote address, paper presentations, lightning talks, a business meeting, continuing education, vendor presentations, and updates from the Medical Library Association, Regional Medical Library, and National Library of Medicine. The difference was in the length of the meeting. The virtual meeting was shorter in length than other MCMLA annual meetings and consisted of two half-day sessions and only one continuing education offering. Registrants were able to attend as individuals or in groups. Many registrants viewed the meeting in groups. Logons to the interface were emailed to the individual attendees, group leaders, and individual presenters prior to the meeting. Even though voice over Internet protocol (VOIP) was available, attendees were encouraged to utilize telephone conferencing for audio stability, which did incur a charge to the attendee. All logons were muted upon signing in to maintain an organized environment. Attendees could interact via the chat, via social media, or in group viewings. A persistent message on the software interface, which displayed the meeting hashtag, encouraged a high level of social media activity throughout the meeting.

The committee learned several lessons in planning and executing the virtual meeting:

- Voting in the online business meeting for individuals attending in groups was an issue. Lastminute decisions regarding this process resulted in manual counting, which delayed the meeting and created confusion. One solution may be to push a link to attendees to a more robust survey software, such as SurveyMonkey.

- Moderators should not move the meeting along too quickly. Viewers typing in questions might not be able to keep the same pace as the moderator.
- Resist the urge to add too much to the meeting and keep it simple. During the planning process, the committee brainstormed many ideas, such as providing gift bags to all viewers, but kept reminding themselves of the chapter goals that were to be achieved: creating a virtual meeting model that was simple and sustainable.

- Educating the membership on what to expect should be a priority. The committee attempted to provide this education, but it was not a concerted effort.

- Even though a virtual meeting results in fewer networking opportunities than an in-person meeting, try to recreate that face-to-face environment through group registrations and to encourage social media participation on multiple platforms. Most attendees participated via group registrations and were active on Twitter and Facebook.

- Organization is the key for successfully coordinating logons for group attendees who are also presenters. A quiet area away from the group is essential for the presenter. On the planning end, this creates extra work to assign and distribute these individual logons, but it is worth it.

- Watching a computer screen requires prolonged sitting and attention, though breaks were scheduled. Two half days of content were plenty. Additionally, several viewers attended the meeting from their libraries. A half-day session allowed them to attend to their work duties as well.

The very nature of a virtual meeting can result in savings. By keeping the meeting simple, MCMLA was able to cover costs and realize a profit. While past annual MCMLA meeting profits have varied widely, the approximately $\$ 4,000$ profit from this virtual meeting was on par with those of the past 5 years. Evaluations showed that the majority of the attendees were satisfied with the meeting content, and $82 \%$ of the respondents would attend a virtual MCMLA annual meeting again. A virtual meeting will now be a part of MCMLA's meeting rotation.

Heather L. Brown, MA, AHIP, hlbrown@unmc.edu, Head of Collection Services, McGoogan Library of Medicine, University of Nebraska Medical Center, 986705 Nebraska Medical Center, Omaha, NE 68198-6705

\section{IMPLEMENTING A DASHBOARD OF LIBRARY STATISTICS}

Submitted by Xiaoyu Sun, MS; Cynthia Robinson, MA, AHIP; Nancy Adams, MLIS; Robyn Reed, MA, 


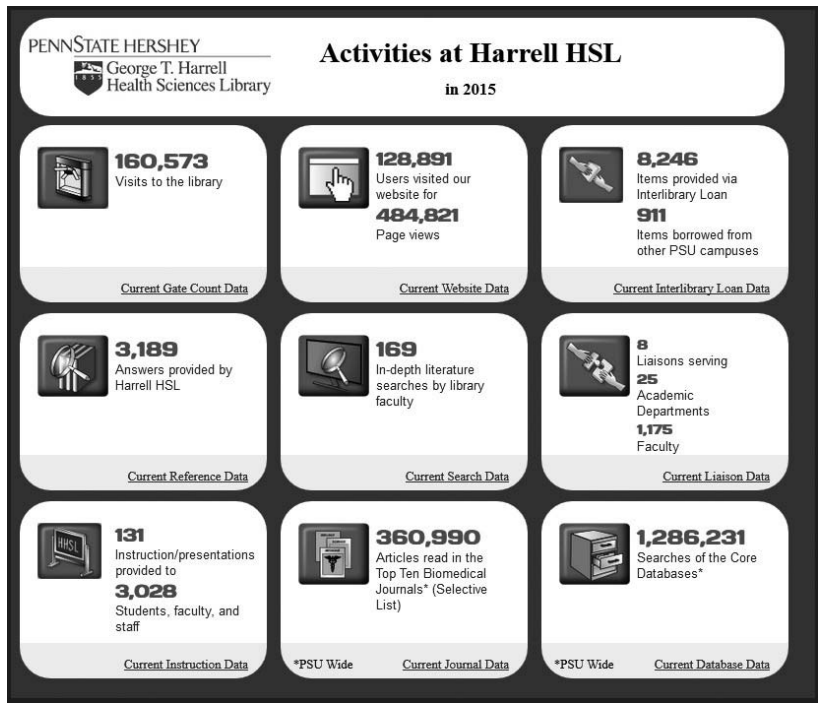

Figure 4

George T. Harrell Health Sciences Library dashboard

\section{MLIS; Esther Y. Dell, AMLS, AHIP; Benjamin Hoover, MLIS; George T. Harrell Health Sciences Library, Penn State College of Medicine}

In February 2015, the George T. Harrell Health Sciences Library launched a digital statistical dashboard highlighting a variety of library activities $<$ http:// www1.libraries.psu.edu/hersheydashboard/ $>$. The dashboard is designed to centralize library statistics for assessment, transparency, and accessibility; provide a platform to raise awareness of library services and programs; and demonstrate the library's impact on the entire institution (Figure 4).

The dashboard was developed by a team led by the library information technology (IT) specialist. With the aforementioned goals for the project in mind, the team began its work by assessing existing products and reviewing options for hosting and displaying statistics on a digital dashboard. In addition, software for the dashboard had to be easy to develop and maintain, be flexible and customizable, and have the ability to integrate with future library systems. Both proprietary and open source products were reviewed for web-based data visualization including Tableau Public < https:// public.tableau.com $>$, Google Charts < https:// developers.google.com/chart/ $>$, and High Charts $<$ http://www.highcharts.com $>$. High Charts, which is freely available for nonprofit projects, was finally chosen for the project. While searching for design ideas on the web, our team found a suitable online dashboard for displaying statistics from Macalester
College $<$ http://www.macalester.edu/library/ dashboard/2014/>. The team liked the format and the idea of using tiles for an "Apple-like" graphic interface. This template was downloaded and used as the basis of development.

A virtual server space for the dashboard is currently hosted by Penn State University Libraries IT. To minimize data management, all statistics are stored using Google Spreadsheets instead of a database. This is necessary due to the age and incompatibility of the some of the systems that are used to gather data in the library. Custom scripts have been developed, which pull statistics from the Google Spreadsheets and generate the HTML. The source code for the dashboard is open source and available on GitHub < https://github.com/psulibraries/dashboard $>$. In the future, the dashboard will be capable of connecting directly to a variety of databases.

Library staff and faculty decided which statistics would be appropriate and feasible for a public dashboard. They share responsibility for supplying and maintaining the data for each panel of the dashboard. The team wanted the dashboard to be as simple as possible and only included metrics information that would be important to library stakeholders, including administrators, faculty, and students. The main dashboard page displays nine panels, each with a distinct data set. The statistics displayed on the main page are yearly totals from the previous calendar year. If a panel is selected by a user, a secondary page appears that reveals more detailed information about each data set for the past three years.

The Harrell HSL dashboard has had an impact on both the library and the campus. Library administrators have used the dashboard to inform decision making. Library metrics are freely available to our stakeholders, increasing transparency about and awareness of library services and resources. The library's dashboard has been added to the main internal dashboard page of the institution, indicating the value of the dashboard to the Penn State Hershey College of Medicine and the Milton S. Hershey Medical Center communities.

Xiaoyu Sun, MS, xsun1@hmc.psu.edu, Information Technology Services and Systems Integration Specialist, George T. Harrell Health Sciences Library, Penn State College of Medicine, H127, 500 University Drive, Hershey PA 17033 


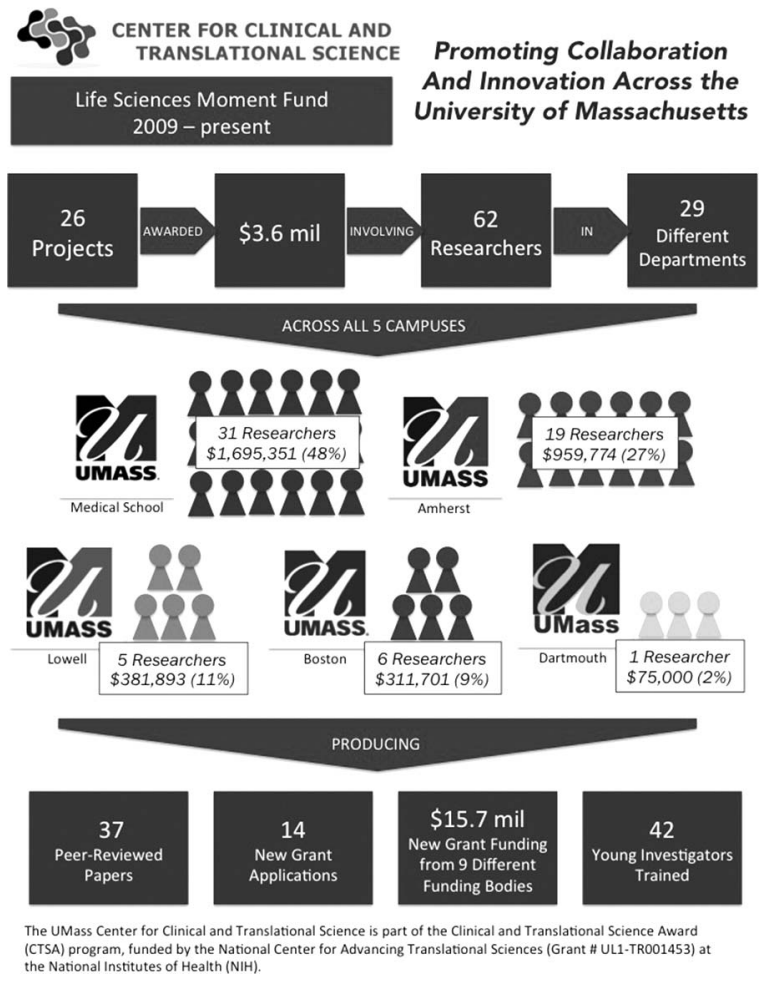

Figure 5

Life Sciences Moment Fund infographic

\section{A PICTURE IS WORTH A THOUSAND DATA POINTS}

Submitted by Sally A. Gore, MS, MSLIS, University of Massachusetts Center for Clinical and Translational Science, University of Massachusetts Medical School

The University of Massachusetts (UMass) Center for Clinical and Translational Science (UMCCTS), founded in 2006, strives to enhance clinical and translational research across the five University of Massachusetts campuses (Amherst, Boston, Dartmouth, Lowell, and UMass Medical School) and its clinical partner, UMass Memorial Health Care. The UMCCTS is funded through a National Institutes of Health (NIH) Clinical and Translational Science Award (CTSA), first received in 2010 and successfully renewed in 2015. The UMCCTS is part of a network of sixty-two NIH-funded centers collaborating to transform the conduct of clinical and translational research across the United States.

The goals of the UMCCTS are to accelerate the translation of basic discoveries into practical, costeffective solutions that improve human health and to develop and support the next generation of leaders in clinical and translational research. As such, the center has a number of key partners and stakeholders with interests in its work, including patients and communities, foundations, biotechnology and pharmaceutical companies, members of the venture capital and philanthropic communities, funding agencies, and academic administrators. Communicating the success of programs and disseminating the discoveries made to these different groups can be a challenge. The different groups look for different outcomes and measures, and communicate in different ways. However, one means of reaching the different groups quickly and easily is via information graphics (infographics).

Graphics, images, and other visual representations of information, when used properly, provide a means of presenting complex stories in a clear and efficient manner. The UMCCTS has leveraged infographics in documents, reports, promotional materials, and a website devoted to performance metrics to improve its ability to demonstrate the impact of its programs to the various stakeholders.

The research and evaluation analyst for the UMCCTS is responsible for tracking, evaluating, and reporting on the center's multiple programs and core services. Beginning with progress reports for funded pilot projects, the analyst used REDCap $<$ http:// projectredcap.org $>$ to develop and manage a secure, online database of variables related to the projects. These data were then analyzed, and the findings summarized in infographics, rather than traditional tables and charts, and published in the center's newsletter and in reports to the dean and chancellor of the Medical School.

This first set of infographics was very well received and resulted in requests for others. Some of these infographics include showing the progress of young investigators, the number of new collaborations formed, the number of scholarly works published and grant awards received, and the number of people served by different research cores (Figure 5). When the UMCCTS website was redesigned, a performance metrics page $<$ http://www. umassmed.edu/ccts/global-components/ performance-metrics/ $>$ was added to house and showcase the growing collection of infographics, creating a place to easily show stakeholders and other interested parties the impact of the center's work. 
Creating graphics requires acquiring and honing skills in areas including both statistics and basic graphic design. One also needs to become comfortable working with tools such as Excel, Tableau, and R (for analyzing data and generating initial visuals), as well as graphic design programs like Adobe Illustrator that make it possible to create print- and web-quality images.

\section{ACKNOWLEDGMENTS}

This project is supported by the University of Massachusetts Center for Clinical and Translational Science, part of the Clinical and Translational Science
Award (CTSA) program, funded by the National Center for Advancing Translational Sciences (grant \# UL1-TR001453) at the National Institutes of Health $(\mathrm{NIH})$. The content is solely the responsibility of the author and does not necessarily represent the official views of the National Institutes of Health.

Sally A. Gore, MS, MS LIS, sally.gore@umassmed.edu, Research and Evaluation Analyst, University of Massachusetts Center for Clinical and Translational Science, University of Massachusetts Medical School, 362 Plantation Street, Worcester, MA 01655-0002 